\title{
CONTRATO PSICOLÓGICO DE FUNCIONÁRIOS DE ORGANIZAÇÔES PÚBLICAS: O QUE CONSTRÓI ESSA RELAÇÃO?
}

\author{
Data de submissão: 11/02/2015 \\ Aceite: 14/02/2017 \\ Bruno Sirotheau de Almeida Eichler ${ }^{1}$ \\ Ana Heloísa Costa Lemos ${ }^{2}$ \\ Diana Rebello Neves ${ }^{3}$
}

\section{RESUMO:}

O objetivo deste trabalho foi identificar os elementos que compõem o contrato psicológico de profissionais com formação superior, egressos do setor privado, que atualmente trabalham em organizações públicas. A tendência recente no mercado de trabalho brasileiro de valorização dos empregos públicos, refletida na crescente procura por vagas no setor, motivou a realização deste trabalho que buscou compreender quais os principais atrativos desses empregos. Os resultados de pesquisa revelam que a busca por uma jornada de trabalho moderada, estabilidade no emprego e boa remuneração orientam essa decisão, mas aspectos como a imagem da instituição, a presença de desafios profissionais e o incentivo à educação também são relevantes para os entrevistados.

Palavras-chave: Contrato psicológico. Empresas públicas. Funcionário público.

1 Possui graduação em Administração de Empresas pela Fundação Getulio Vargas (FGV), mestrado em Administração de Empresas pela Pontifícia Universidade Católica do Rio de Janeiro (PUC-Rio). Administrador na Área de Energia do Banco Nacional de Desenvolvimento Econômico e Social (BNDES). Rio de Janeiro RJ. Brasil. E-mail: bruno.eichler@gmail.com

2 Possui graduação em Ciências Políticas e Sociais pela Pontifícia Universidade Católica do Rio de Janeiro, PUC-Rio, mestrado em Administração pela Fundação Getúlio Vargas, FGV e doutorado em Sociologia pelo Instituto Universitário de Pesquisas do Rio de Janeiro, IUPERJ. Professora da Escola de Negócios da Pontifícia Universidade Católica do Rio de Janeiro (PUC-Rio), no Brasil. É a atual Coordenadora da Divisão de Gestão de Pessoas e Relações de Trabalho da Associação Nacional de Pós-Graduação e Pesquisa em Administração (ANPAD / Brasil). Rio de Janeiro - RJ. Brasil. E-mail: aheloisa@iag.puc-rio.br 3 Possui graduação em Administração de Empresas pela Pontifícia Universidade Católica do Rio de Janeiro (PUC-Rio), mestrado em Administração de Empresas pela PUC-Rio, doutorado em Administração de Empresas pela Universidade do Grande Rio (UNIGRANRIO). Professora da Universidade de Vassouras/ FAMIPE. Vassouras, Rio de Janeiro. Brasil. E-mail: dianarebello@hotmail.com 


\section{INTRODUÇÃO}

Observa-se uma tendência recente no mercado de trabalho brasileiro de valorização dos empregos públicos, refletida tanto no aumento do número de vagas ofertadas no setor, quanto na crescente procura por essas posições. Entre 2012 e 2013, houve um incremento de $44,4 \%$ da oferta de vagas em concursos públicos, passando de 90 mil, no primeiro ano, para 130 mil, no segundo. Essa oferta de vagas não refletiu somente a reposição de funcionários, mas também uma elevação da quantidade de empregos públicos no Brasil, já que, de acordo com o Instituto Brasileiro de Geografia e Estatíticas (IBGE), o percentual de militares e funcionários públicos aumentou de 7,3\% para 8,2\% na força de trabalho do país, entre os anos de 2008 e 2016.

Apesar do incremento na oferta de vagas nesse setor, a concorrência por esses postos não diminuiu, até o momento. De acordo com a Associação Nacional de Proteção e Apoio ao Concurso (ANPAC), 6,7 milhões de pessoas se inscreveram em concursos públicos, nas esferas federal, estadual e municipal, entre os anos de 2005 e 2007 . Essa mesma associação indicou, em 2015, que essa busca aumentou e que, anualmente, entre 10 e 12 milhões de pessoas se inscrevem em concursos, nessas três esferas.

Este interesse pelo emprego no setor público aparece tanto entre os novos entrantes no mercado de trabalho, jovens profissionais recém saídos das universidades, como entre trabalhadores experientes que atuam no setor privado, mas que desejam migrar para a área pública. De acordo com estudo do IBGE apresentado em maio de 2013, esse movimento pode ser justificado, em parte, pelo fato de as remunerações no setor público serem $46 \%$ maiores do que as da iniciativa privada. Essa pesquisa, realizada em 2011, identificou que o salário médio do setor público esse ano foi $R \$ 2.478,21$, enquanto as entidades empresariais pagaram $R \$ 1.592,19$.

Em matéria do jornal "O Globo" (AMORIM, 2013), foi destacado o fato de que o Banco Nacional de Desenvolvimento Econômico e Social (BNDES) registrou, no concurso promovido em março de 2013, o maior número de inscritos da história desse banco, com um total de 137.989 candidatos. Desse quantitativo, 63.865 participantes se inscreveram nos 12 cargos de nível superior abertos pela instituição. Essa mesma matéria informa, com base em entrevistas realizadas com alguns desses concorrentes, que o salário inicial de $\mathrm{R} \$ 9.182 .01$ não é o único motivador para quem presta o concurso: questões como ambiente de trabalho, imagem e valores da empresa também reforçam o interesse pela organização.

Esse movimento sugere que as instituições públicas parecem oferecer um conjunto de fatores que se mostram atrativos aos profissionais e que motivam, inclusive, indivíduos com carreiras estabelecidas no setor privado a migrarem para a área pública e reiniciarem seus planos de carreira nesse setor. Côrtes e Silva (2006) identificaram a estabilidade como um fator de destaque na opção por essa migração, por exemplo. Por esse motivo, entender o que vem atraindo tantos profissionais para essas instituições é tema de interesse tanto para o setor público - que precisa contar com profissionais altamente qualificados, quanto para o setor privado, que vem perdendo pessoal para o primeiro.

A observação deste cenário motivou os autores a realizarem um estudo que buscou compreender quais são os atrativos das empresas públicas que despertam o interesse de um número expressivo de profissionais com formação universitária, com ênfase naqueles que construíram suas carreiras, inicialmente, na iniciativa privada. Elegeu-se este grupo específico por se entender que a decisão de trocar a iniciativa privada pelo setor público indica uma opção, feita com base em avaliações positivas acerca deste setor, e não um direcionamento motivado por falta de oportunidade de trabalho na inciativa privada. Foram entrevistados, portanto, indivíduos 
que escolheram fazer a mudança de um setor para o outro, e não aqueles que ingressaram nas organizações públicas por dificuldades de inserção no setor privado, o que reforça a constatação da valorização que a área pública vem recebendo, nos últimos anos. A análise está focada na construção dessa relação em instituições públicas federais prestigiadas na sociedade, que apresentam processos seletivos concorridos, boa remuneração inicial e atividades consideradas atraentes pelos concorrentes a esses cargos, isto é, empresas que simbolizam o emprego público "ideal" no imaginário do trabalhador brasileiro: salário elevado, prestígio social, estabilidade e trabalho estimulante. Neste sentido, o presente artigo procurou contribuir para o entendimento dos principais motivos que levaram profissionais que atuavam na iniciativa privada a desejarem conquistar um emprego no setor público.

Dessa forma, para compreender melhor os atrativos das organizações públicas para estes profissionais optou-se por analisar os principais aspectos delineadores do contrato psicológico de profissionais que atuavam na iniciativa privada e migraram para o setor público, tendo sido entrevistados funcionários do Banco Central, PETROBRÁS e BNDES. O contrato psicológico constitui a relação de troca entre empregado e empregador, e a escolha desse construto decorre do fato de acreditar-se que ele é um aspecto importante para se entender o que atrai e o que retém um trabalhador, a uma determinada organização. Neste sentido, o presente trabalho dá continuidade e amplia estudos nacionais recentes voltados para analisar o contrato psicológico estabelecido entre profissionais do setor público e suas respectivas organizações, como o trabalho de Wetzel (2001) acerca das transformações do contrato psicológico em empresas privatizadas e, em especial, o de Cortês e Silva (2006) sobre o processo de construção deste contrato em uma empresa estatal, em cujo quadro conceitual o presente trabalho se baseia. No que diz respeito às contribuições que o presente trabalho procurou trazer, acredita-se que conhecer os motivos que vêm atraindo profissionais, egressos do setor privado, para o setor público contribui tanto para o entendimento da atratividade que este setor vem exercendo sobre os trabalhadores brasileiros, quanto para desvelar as causas subjacentes à migração de profissionais qualificados do setor privado, para o público. Ademais, apesar de o setor público ser frequentemente objeto de pesquisas acadêmicas (MOLON, MELLO e TORRES, 2013; RORATO e DIAS, 2011; SILVA e GONÇALVES, 2011), poucos são os estudos, à exceção dos supracitados Wetzel (2001) e Cortês e Silva (2006), dedicados a analisar o contrato psicológico estabelecido entre funcionários públicos e empresas, no Brasil. Finalmente, entende-se que pesquisas que ampliem a compreensão das expectativas de profissionais acerca de suas condições de trabalho possam ser úteis para subsidiar a gestão de pessoas de ambos os setores .

Para apresentar e debater os achados da pesquisa, estruturou-se o presente artigo em cinco tópicos, incluindo esta parte introdutória. O segundo tópico foi dedicado a discutir a literatura sobre o contrato psicológico. No terceiro, são abordados os aspectos metodológicos da pesquisa. No quarto tópico, interpretam-se os resultados da pesquisa à luz da análise de conteúdo. No último tópico, são apresentadas as considerações finais, incluindo as limitações do estudo e sugestões para futuras investigações.

\section{PERSPECTIVA TEÓRICA}

\subsection{Definição de contrato psicológico}

O termo contrato psicológico foi utilizado pela primeira vez por Argyris (1960). O au- 
tor acreditava que empregados e organizações criavam contratos psicológicos que permitiam a expressão e gratificação das necessidades de cada um. Em outras palavras, se os empregados sentem que seus gestores estão respeitando seu direito de se desenvolver, crescer e usar sua própria iniciativa, então, em troca, os funcionários também irão respeitar o direito de evoluir da organização. Para Argyris (1960), se os empregadores não interferem demais nas ações dos empregados, respeitam sua cultura ou normas do grupo e deixam que eles façam o seu trabalho, a tendência é que tenham um desempenho melhor. Portanto, contanto que os empregadores mantenham sua parte do acordo, os empregados estarão preparados para trabalhar produtivamente.

Em linha com esse entendimento, Conway e Briner (2005) e Rousseau (1989;1995) definem o contrato psicológico como uma relação de troca entre empregado e empregador. Rousseau (1989) desenvolve esse conceito, enfatizando as crenças que um indivíduo tem a respeito de um acordo de troca traçado entre ele e seu empregador. Essas crenças são baseadas em promessas, que podem ser explícitas ou implícitas, e que, com a consolidação do contrato, ganham força e passam a compor um modelo mental que guia essa relação. Guest (2004), por sua vez, destaca o caráter único desse tipo de acordo, já que seus termos são negociados individualmente, no momento da contratação, e essa negociação continua, posteriormente. Os contratos psicológicos influenciam os esforços que os empregados fazem em prol da empresa, bem como sua aceitação de mudanças na organização e de comportamentos do seu empregador, o que inclui possíveis falhas da empresa em cumprir alguma promessa (LEE et al., 2011).

Levinson et al. (1962) descrevem o contrato psicológico como o contrato não escrito, como a soma das expectativas mútuas entre a organização e o empregado. $O$ conceito é utilizado para destacar expectativas implícitas e não ditas que são anteriores à relação entre empregador e empregado. Schein (1965) enxerga o contrato psicológico como um caminho para analisar o relacionamento de empregados e empregadores. Para o autor, os empregados avaliam o contrato psicológico observando se existe alguma correspondência entre as suas expectativas e as das organizações.

Os contratos psicológicos influenciam os esforços que os empregados fazem em prol da empresa, bem como sua aceitação face à mudança na organização e reações a possíveis falhas do empregador em cumprir alguma promessa (LEE et al. 2011).

O foco da teoria do contrato psicológico direciona-se, predominantemente, para a perspectiva do empregado e, o presente trabalho, alinha-se com esse pensamento. Rousseau (1995; 2005) reforça a ideia de que o foco do debate deve estar voltado para o funcionário, já que as empresas são entidades abstratas e, por isso, não podem estabelecer um contrato psicológico; apenas os agentes dessas organizações teriam a capacidade de manter um contrato psicológico com os funcionários.

Conway e Briner (2005), no entanto, destacam como um problema a pouca atenção direcionada à perspectiva da organização, nos estudos sobre contratos psicológicos, pois, apesar de concordarem com a definição da empresa como uma entidade abstrata, todo o discurso que envolve o construto do contrato psicológico estabelece uma relação do empregado com essa entidade, ou seja, a empresa acaba sendo tratada como detentora de um contrato com o trabalhador. 


\subsection{O contrato psicológico como um processo}

O contrato psicológico pode ser visto como um processo em que há trocas contínuas entre as partes, pautadas por eventos significativos, que vão ocorrendo ao longo do tempo. Guest (2004) argumenta que o contrato psicológico se mostrou útil para compreender as relações de trabalho, e essas relações são, em sua maioria, implícitas e não escritas, o que faz com que as partes tenham diferentes interpretações sobre elas, que se modificam ao longo do tempo.

Conway e Briner (2005), por sua vez, destacam algumas características que definem processos em geral, e que também estão presentes no contrato psicológico. Primeiramente, os processos tratam de uma sequência de eventos, que são acontecimentos no trabalho que causam algum tipo de reação, seja afetiva, cognitiva ou comportamental, que pode ser localizada no tempo e espaço. Uma segunda característica refere-se ao fato de que, quando se observam os processos, múltiplos níveis de análise entram em cena, e esses elementos vão desde questões como o tempo, até a perspectiva dos envolvidos nesses processos (que pode ser o indivíduo, o grupo ou a organização, por exemplo). Por fim, argumenta-se que tanto o tempo de duração de um evento quanto a duração dos efeitos que este causa pode variar consideravelmente, exemplificando: um chefe pode humilhar publicamente um funcionário em alguns minutos, mas o efeito deste episódio pode durar meses. Rousseau (1989) indica que as expectativas formadas durante as interações formam padrões futuros de reciprocidade.

Robinson, Kraatz e Rousseau (1994) destacam que as percepções dos indivíduos, que compõem o contrato psicológico, vão se modificando ao longo do tempo. Esse fato é decorrente do movimento contínuo no qual uma das partes oferece um benefício e, em contrapartida, a outra paga um custo. Esses movimentos constantes de oferecimento de diferentes benefícios e pagamento de custos vão modificando os termos do contrato psicológico. Os autores concluem que, durante os dois primeiros anos de emprego, essa relação se remodela de modo que os empregados percebem dever menos à organização do que pensavam dever no momento da contratação, ao mesmo tempo em que entendem que a organização lhes deve mais.

Com o objetivo de compreender melhor a natureza processual do contrato, Côrtes e Silva (2006) propuseram um quadro conceitual que analisa a construção do contrato psicológico dos indivíduos com as empresas (Figura 1). Esse modelo foi estruturado a partir do estudo de caso de uma empresa estatal do setor de energia, e o processo de construção do contrato é dividido em três etapas: a decisão de ingresso na organização; o ajuste inicial do contrato psicológico e a reavaliação desse contrato. Apesar de elaborado tendo como base a construção do contrato em uma empresa estatal, os autores destacam que esse processo se desenvolve, de forma análoga, em organizações de outros setores, podendo ser utilizado para analisar o estabelecimento de contratos psicológicos, em diferentes organizações. A consideração dos autores, acerca da validade do modelo para as demais organizações, está alinhada com as considerações de Guest (2004), Conway e Briner (2005), Robinson, Kraatz e Rousseau (1994), anteriormente destacadas, que enfatizam o caráter processual - e não estático - da construção dos contratos psicológicos. Por tratar-se de uma relação, o contrato psicológico é dinâmico, modificando-se na medida em que os laços com as organizações vão evoluindo. 
Figura 1 - Quadro conceitual sobre a construção do contrato psicológico

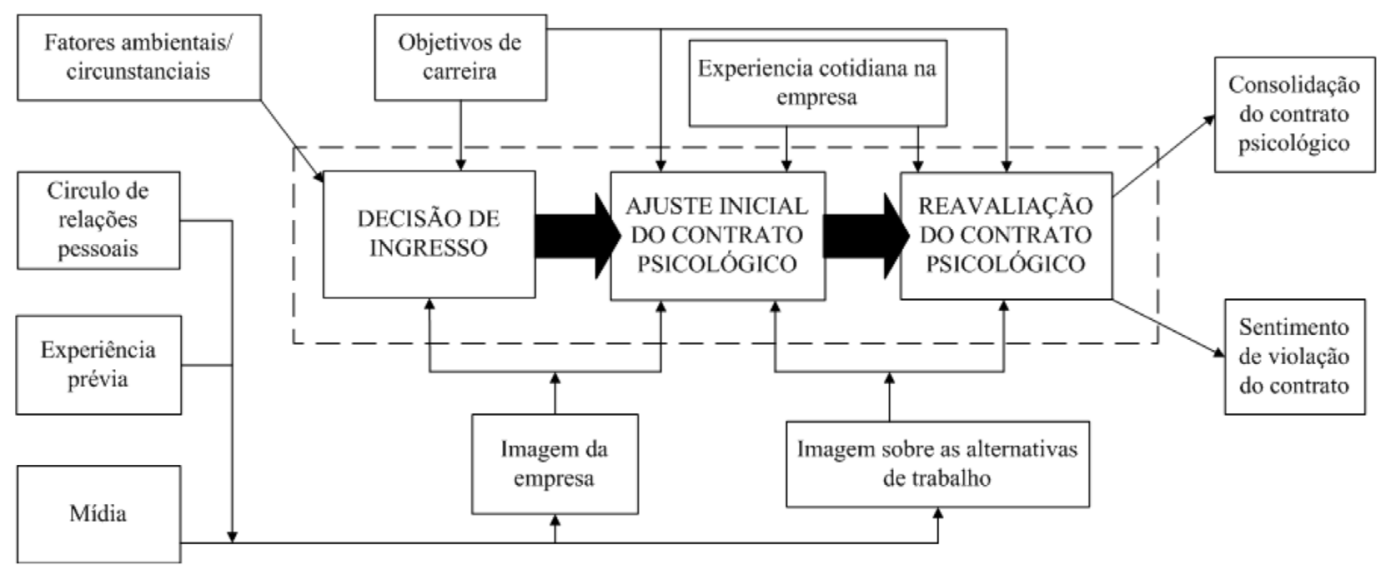

Fonte: Côrtes e Silva (2006:15).

Na primeira etapa, os autores destacaram a importância de fatores ambientais como o mercado de trabalho e a opinião da família na decisão de ingresso na organização. Objetivos pessoais como as expectativas sobre sua carreira também surgiram como fatores determinantes dessa decisão. Além disso, a imagem da empresa foi indicada como influenciadora dessa etapa, assim como da seguinte, em que se ajusta o contrato.

No segundo momento, de ajuste inicial do contrato psicológico, o indivíduo passa a conhecer melhor a empresa e o seu ambiente, comparando as características positivas e negativas da organização e compondo o contrato psicológico. Nesta etapa, experiências passadas e alternativas de trabalho entram em cena na composição dessa relação.

No momento de reavaliação do contrato psicológico, o funcionário tem mais recursos para avaliar sua relação com a empresa e torna-se mais crítico sobre o que julga que ela oferece. Nesse ponto, o empregado tem insumos para avaliar se o discurso enunciado no momento da contratação é consistente com a realidade atual da empresa, e as alternativas de trabalho mais uma vez mostram-se presentes na reavaliação do contrato, contribuindo para o olhar crítico em relação à empresa.

Com base nesses três estágios pontuam-se momentos importantes de estabelecimento do processo do contrato psicológico. Esse olhar do construto pela ótica do processo provê uma visão mais estruturada que pode auxiliar, de forma prática, a gestão das organizações (CONWAY e BRINER, 2005).

\subsection{Construção e alteração do contrato psicológico}

Conforme destacado no item anterior, existem fatores que vêm de fora da organização e que influenciam a construção do contrato psicológico, como a expectativa que os novos funcionários trazem ao ingressarem na mesma. Essas expectativas são formadas pelo que se espera em relação ao novo trabalho e se baseiam em experiências anteriores que os indivíduos tiveram, ajudando a modelar o contrato (CONWAY e BRINER, 2005). A opinião de pessoas que não compartilham o mesmo empregador ou ambiente 
de trabalho sobre a organização pode, também, ajudar a formar o acordo. $E$, de forma mais ampla, fatores macroambientais econômicos ou legais afetam esse tipo de relação.

Conforme destaca Guest (2004), em um sistema organizacional em turbulência são necessárias ferramentas que possam ser utilizadas para avaliar e reavaliar as relações de trabalho e os desdobramentos dessas relações, tanto para a empresa quanto para o empregado. As obrigações entre as partes podem mudar, por uma série de motivos, mas duas razões inerentes a esse tipo de relação destacam-se. Primeiramente, a visão do empregado certamente terá modificado, quando comparada à sua visão no momento da contratação; o desenvolvimento da relação de troca entre as partes vai se adaptando às mudanças ambientais e à percepção do empregado varia, em função disso. Essa percepção do funcionário, que avalia tanto o seu próprio comportamento quanto o do empregador, altera o contrato (ROBINSON, KRAATZ e ROUSSEAU, 1994).

Dando continuidade a esse raciocínio, os autores argumentam que, de acordo com a norma da reciprocidade, o recebimento de um benefício por uma das partes é gerado por um custo da outra parte, e contínuos ciclos de pagamento e recebimento ao longo do tempo criam uma grande quantidade e diversidade de obrigações estabelecidas entre eles. Deve-se considerar, também, que indivíduos buscam obter um saldo positivo nessa troca, evitando ficar endividados com a outra parte. Outro fator associado a esse comportamento é o grau de maturidade da relação entre empregador e empregado, pois quanto mais cresce esse grau, mais se espera que cresçam as obrigações, intensificando-se, assim, a troca.

Rousseau (1995), por sua vez, afirma que as alterações no contrato variam de mudanças sutis e imperceptíveis nos entendimentos até as mais traumáticas, afetando tanto as experiências dos indivíduos quanto o dinamismo dos grupos de trabalho. Segundo a autora, as alterações no contrato ocorrem de diversas maneiras. Fatores externos e internos que afetam o trabalho das pessoas podem interferir no contrato, levando a alterações que variam de pequenas adições, modificações e ajustes nos termos do contrato, até a reformulação radical de todo o contrato. Essas mudanças assumem duas formas: acomodação evolutiva ou transformações revolucionárias.

Rousseau (1995) explica que a acomodação faz ajustes no contrato já existente. Ela modifica, torna mais claro, substitui ou expande termos já existentes no contrato. Ocorre quando os mesmos esquemas permanecem, apesar das mudanças nas condições de trabalho reconhecidas. Ainda segundo a autora, quando há um bom relacionamento entre as partes do contrato, as mudanças são mais suscetíveis de serem interpretadas como existente no âmbito do contrato. $\mathrm{O}$ bom relacionamento leva à mudança por acomodação por dois fatores: as partes não estão procurando ativamente por violações do contrato, e um bom relacionamento inclui algumas relações de termos do contrato, que aumentam a zona de aceitação. Relacionamentos com um histórico positivo manifestam uma boa vontade em ser flexível, o que torna mais fácil, para ambas as partes, solicitarem mudanças.

Em relação às mudanças por transformação, Rousseau (1995) explica que estas marcam uma alteração fundamental na natureza da relação entre as partes, redefinindo tanto as relações, quanto o contrato em que a mesma se baseia. Nas organizações contemporâneas, existe pouco consenso sobre a natureza da mudança, mas existe um entendimento de que as organizações estão mudando de forma sem precedentes. Por isto, as mudanças notadas pelos comentaristas contemporâneos são transformações radicais no contrato psicológico. Nestas transformações, um contrato já existente, às vezes por violação, outras vezes por realização, deixa de existir, e um novo é criado. As perdas são reais, e os custos são altos, mas os ganhos também podem ser. Existe uma linha tênue entre violação e transformação.

Um ponto importante para o entendimento deste trabalho é analisado por Rous- 
seau (1995), quando a autora explica que a passagem do tempo traz substanciais mudanças psicológicas e sociais. As necessidades dos trabalhadores e das organizações podem mudar com a idade e os novos papéis e responsabilidades da vida adulta. $O$ tempo pode transformar uma atividade que antes era normal, em algo quase impossível de se realizar. Trabalhadores com mais de trinta anos, com responsabilidades familiares, podem achar que as condições de trabalho que eram bem vindas aos vinte anos tornam-se difíceis de serem cumpridas. Uma pessoa dedicada e motivada pode acabar comprometendo sua dedicação ao trabalho, em função do aumento da responsabilidade familiar. Essas mudanças podem ocorrer de forma mais fácil quando as pessoas fazem parte de um grupo de trabalho que compartilha das mesmas experiências.

A autora diz ainda que, para muitas pessoas, mudanças em suas vidas pessoais modificam a maneira como enxergam o trabalho como um todo. Essas mudanças podem ser alterações sutis na alocação do tempo ou ajustes mais intensos nas atividades. Não obstante, as mudanças podem criar uma nova definição das próprias responsabilidades do trabalho. O ciclo de vida pode mudar o significado dos termos do contrato.

McFarlane e Tetrick (1994), por sua vez, afirmam que a violação do contrato psicológico ocorre quando o empregado experimenta uma discrepância entre o real cumprimento das obrigações pela organização e as promessas anteriormente feitas pelas mesmas. $O$ grau de violação experimentado depende do tipo, do grau de divergência e do fato de a organização ser ou não responsável pela violação.

Conway e Briner (2006) destacam, dentre as possíveis causas para a violação de um contrato psicológico, as práticas inadequadas de gestão de recursos humanos; a ausência de suporte por parte da organização ou de seus supervisores; e a percepção de tratamento desigual entre os funcionários.

Robinson e Morrison (1995) destacam que a reestruturação, downsizing e terceirização, que ocorreram como resultados da concorrência internacional e dos avanços na tecnologia, tornam cada vez mais difícil para as organizações cumprirem os contratos psicológicos, mesmo quando estas têm a intenção de fazê-lo. Quando as organizações não cumprem as suas promessas, espera-se que os funcionários reduzam suas contribuições e tenham atitudes negativas com relação às organizações.

\section{ASPECTOS METODOLÓGICOS DA PESQUISA}

Tendo em vista o objetivo de compreender o aumento do interesse da mão de obra, com formação superior, no Brasil, pela esfera pública, com ênfase naqueles originalmente atuantes no setor privado, foram estudados os fatores formadores dos contratos psicológicos de funcionários de empresas públicas egressos do setor privado. Optou-se, neste trabalho, por uma estratégia de investigação de natureza qualitativa (GODOY, 1995). Com relação à escolha dos sujeitos, foram entrevistadas treze pessoas, provenientes de três instituições federais localizadas no Rio de Janeiro: o Banco Nacional de Desenvolvimento Econômico e Social - BNDES, a Petróleo Brasileiro S/A - PETROBRAS, e o Banco Central do Brasil - BACEN. Como foi citado anteriormente, essas empresas foram escolhidas por oferecerem salários elevados e simbolizarem o "ideal" do emprego público no imaginário coletivo. Acreditou-se, portanto, que a opção por trabalhar nessas empresas, cujas vagas são disputadas, conforme destacado na introdução deste trabalho, revelaria um forte desejo dos profissionais em ingressar nessas organizações. A este aspecto acrescenta-se o fato de os entrevistados serem jovens e egressos da iniciativa privada, o que reforça a opção pelo emprego público. Os sujeitos foram acessados por meio da rede de 
relacionamento do pesquisador e de indicações feitas pelos primeiros entrevistados com base no perfil solicitado.

Foram previamente selecionados participantes com idade até 40 anos a fim de diminuir a possibilidade de inclusão de pessoas que estivessem buscando o setor público pela dificuldade de recolocação profissional no mercado privado. Ao entrevistar pessoas que possuem entre 27 e 40 anos, acreditou-se que se estava dialogando com indivíduos que tiveram a intenção de ingressar no setor público, não necessariamente por falta de oportunidades no setor privado, mas por vislumbrarem aspectos atraentes na área pública. Considerou-se um tempo mínimo de permanência de dois anos na instituição pública, buscando garantir que os entrevistados tivessem vivido as três fases do contrato psicológico definidas por Côrtes e Silva (2006), que serviu para estruturar a análise. Por isso, esses indivíduos têm uma média de 5,4 anos na empresa atual (mínimo de dois e máximo de 12 anos). Foram entrevistadas treze pessoas, no total, pois constatou-se que, a partir do décimo entrevistado, as falas convergiam, não surgindo temas novos em seus relatos.

O processo de análise do material coletado, baseado no método de análise de conteúdo (BARDIN, 2006), compreendeu a leitura e a organização dos dados permitindo a construção de categorias, a posteriori, que ajudaram a identificar os principais aspectos que delineiam as três fases do contrato psicológico (CÔRTES e SILVA, 2006), estabelecido entre funcionários que trabalham em empresas públicas e as organizações nas quais estão inseridos. Essas categorias identificaram os valores e atitudes dos empregados que conformaram a construção do contrato psicológico desses indivíduos com suas respectivas empresas.

\section{ANÁLISE E INTERPRETAÇÃO DOS RESULTADOS: CON- STRUINDO O CONTRATO PSICOLÓGICO COM A OR- GANIZAÇÃO PÚBLICA}

Para organizar a análise, optou-se pela utilização das três etapas do contrato psicológico propostas no modelo de Côrtes e Silva $(2006)$, que orientaram a constituição de três grandes tópicos: a decisão de ingresso na organização, o ajuste inicial do contrato psicológico e a reavaliação desse contrato. Em cada um desses tópicos, são destacados os fatores identificados pelos entrevistados como mais significativos para a constituição do contrato psicológico, em cada uma das etapas analisadas.

\subsection{Fatores relacionados à decisão de ingresso no setor público}

Como ressalta Rousseau (1996), o contrato psicológico começa a ser formado antes mesmo do ingresso do funcionário na organização. Por este motivo, os entrevistados foram indagados acerca dos aspectos que os motivaram a fazer o concurso público para ingressar na empresa em questão. Dos relatos obtidos, os principais motivos mencionados foram a jornada de trabalho "moderada", a perspectiva de ter estabilidade no emprego, a remuneração atraente e a imagem positiva da empresa. Estas foram, em linhas gerais, as características do trabalho vislumbradas que, segundo os entrevistados, influenciaram a opção pelo ingresso nessas organizações.

\subsubsection{Jornada de trabalho}

Quando solicitados a descrever quais fatores os atraíram em busca do emprego público, os entrevistados apresentaram recorrentemente a questão da jornada de trabalho reduzida ou 
mesmo "moderada" como uma vantagem:

Logo no edital (do concurso público) já mostrava uma carga de trabalho de sete horas por dia, enquanto eu trabalhava, no mínimo, oito. Só isso já mostrava uma redução. Eu não esperava também fazer horas extras. (E2)

A jornada foi um dos itens mais citados por ser entendida tanto como um fator de atração para o cargo público quanto como um fator negativo para a permanência nas empresas privadas. É válido, portanto, ressaltar que essa temática está ligada a um momento de reflexão sobre o ingresso no setor público e, por isso, vem carregada das impressões sobre as experiências vividas pelos participantes no ambiente privado e pelas expectativas a respeito do trabalho no novo setor. Do total de treze participantes, onze trouxeram esse tópico à tona:

O que me atraía muito era essa questão de conseguir organizar melhor a minha vida, de conseguir marcar um médico, conseguir fazer atividade física. (E1)

Pode-se dizer que, dentre os entrevistados, havia tanto aqueles que desejavam trabalhar um pouco menos, fato possível em empresas que contavam com jornadas um pouco menores do que as quarenta semanais, como aqueles que ansiavam, tão somente, por "ter hora para sair", isto é, por trabalhar em uma empresa na qual fosse possível trabalhar "apenas" oito horas diárias.

(...) Ter um planejamento de que você vai poder trabalhar, sair todos os dias mais ou menos na mesma hora, talvez um dia ou outro ter que ficar mais. (E7)

Eu vi que não estava muito disposto na prática a dedicar $100 \%$ da minha vida ao aspecto profissional. (E3)

À jornada alongada enfrentada nas empresas do setor privado, os entrevistados associam também a questão da carga de trabalho, a grande pressão envolvendo as tarefas e as fortes cobranças por resultados. $O$ discurso dos participantes indica que essas exigências percebidas ocorrem de uma forma não balanceada, o que abre espaço para a reflexão sobre a reciprocidade da relação.

(...) Eu botei na balança. Estava sendo demais (...) Apesar de que lá eu achava que ia ter um crescimento mais rápido, eu achei que aquele ritmo tinha um prazo de validade, que eu não ia aguentar muitos anos aquilo. (E4)

Foi uma época muito difícil da minha vida. Foi a época que eu resolvi que não era aquilo que eu queria mais para minha vida. Porque eu não aguentava mais. Só pensava assim: 'meu Deus, vou ficar velha. Como é que eu vou ficar velha aguentando esse pique de trabalho? (E13)

Conforme afirma Rousseau (1996), o contrato psicológico começa a se formar antes mesmo do ingresso do trabalhador na organização, com base em experiências anteriores. No caso dos entrevistados, a expectativa por trabalhar um pouco menos e com menor pressão, nas organizações públicas, estava fortemente associada à experiência anterior no setor privado, marcada por excesso de horas de trabalho e pressão.

\subsubsection{Estabilidade no emprego}

A estabilidade no emprego, decorrente do fato de ser mais difícil ser demitido das empresas públicas em questão, foi outra temática trazida por todos os participantes não apenas como um ponto atraente nessas organizações, mas também como um dos importantes fatores motivadores na sua decisão de mudança profissional: 
O longo prazo quer dizer estabilidade. Na iniciativa privada você não tem nenhuma garantia de futuro, não é? A não ser que você seja muito bem relacionado, o que não era o meu caso. (E9)

Mais uma vez os entrevistados trazem à tona sua experiência anterior para explicar suas expectativas a respeito da empresa pública. Dessa forma, o discurso sobre a ideia de segurança no emprego, nas organizações do governo, vinha conjugado com as impressões sobre a experiência no setor privado. A instabilidade nesse setor foi abordada, de alguma maneira, por todos os entrevistados:

$\mathrm{Na}$ empresa em que eu trabalhava, todos os dias falava-se em demissão, porque a empresa estava passando por uma reestruturação, então não tinha um dia em que você não ouvia um colega falando de algum assunto ligado à demissão de alguém. (E5)

A valorização da estabilidade indica o interesse dos indivíduos em estabelecer uma relação de longo prazo com suas organizações. $O$ entrevistado 2 identifica que no mercado privado o "carreirismo", entendido como a constante mudança de empregador, é desgastante e necessário para a manutenção de bons salários por parte do empregado, o que está em linha com a perspectiva transacional de relação de trabalho apresentada por Dabos e Rousseau (2004):

No mercado privado você está em constante mudança de trabalho, saindo de uma empresa para outra. Não aguentava mais fazer seleção, fazer dinâmica, fazer entrevista. (E2)

A entrevistada 1 caracteriza o processo da mesma maneira, exemplificando que se estivesse hoje em uma empresa privada deveria estar atenta para o momento correto de buscar oportunidades fora dela:

Tinha que me preocupar em ficar avaliando minha carreira a todo o momento. Qual o melhor momento de sair? Agora? Depois? Quanto tempo fico? Vou pra onde? (E1)

Esses participantes entendiam que esse tipo de comportamento, considerado desgastante, não seria requerido no ambiente público. Apesar de não ser incomum que funcionários públicos façam diversos concursos, em busca de posições cada vez melhores e mais bem remuneradas, não se registrou, nos relatos dos entrevistados, esta intenção.

A busca por um emprego estável e com uma jornada de trabalho "normal", aspectos que contrastavam com as condições vivenciadas pelos entrevistados em seus empregos anteriores, reforçam a consideração de Côrtes e Silva (2006) a respeito do impacto da experiência de trabalho anterior na decisão de ingresso em uma nova organização. Esse contraste, favorável à relação estabelecida com a nova empresa, sinaliza a constituição de bases capazes de consolidar o contrato psicológico em estudo.

\subsubsection{Remuneração atraente}

A busca de um contrato mais relacional com o empregador, possibilitado por um vínculo mais estável, vem acompanhada da valorização do salário. Esse foi mais um item destacado por todos os entrevistados como fundamental para a decisão de ingresso na área pública. A maior parte dos entrevistados relataram terem tido aumentos superiores a $100 \%$ quando entraram em organizações públicas (houve um caso de aumento de $200 \%$ e outro de $300 \%$ ), quando comparados com seus salários anteriores na área privada: 
Outros dois indicaram que o salário foi um fator importante, mas não especificaram o impacto da mudança. Somente dois participantes informaram não terem tido mudança salarial significativa, mas mesmo assim, mencionaram a remuneração como fator relevante em sua decisão de ingresso:

O salário sem dúvida foi importante. Na época o meu salário se equiparava ao que eu ia ganhar aqui (...) Era praticamente elas por elas. (E4)

Alguns entrevistados indicaram que os valores salariais praticados nas empresas privadas em que trabalharam anteriormente estavam aquém de um padrão de vida almejado pelos mesmos. Este padrão desejado seria conseguido somente no longo prazo e com recompensas incertas. Essa conjugação de fatores serviu também como motivadora no caminho da área pública:

(...) Na época, eu pensei: não tenho condições de ter uma família hoje, se tiver alguma pretensão eu preciso dar um upgrade na minha vida, e a forma mais imediata de fazer isso acabou sendo o concurso público. (E6)

Esses funcionários identificaram um desequilíbrio quando compararam suas contribuições para as organizações no setor privado com as respostas das mesmas, principalmente no que tange à remuneração:

(...) O meu salário era muito baixo mesmo e crescia de forma devagar (...) Eu só estaria ganhando o salário inicial da empresa $X$ talvez em mais uns três anos de trabalho. (E1) Eu gosto de usar aquela expressão, você usa uma cenourinha na frente que você vai ter um cargo maior então você vai ganhar mais, mas você só vai ter muito dinheiro quando chegar sócio, que é uma coisa que leva 15, 16 anos, a maioria sai no meio do caminho e mesmo quando você está perto de chegar tua remuneração ainda é muito baixa. (E10)

O desequilíbrio percebido é especialmente forte quando a relação entre o empregado e a empresa é transacional (ROBINSON, KRAATZ e ROUSSEAU,1994), o que parece ser o caso das relações estabelecidas entre os entrevistados e seus antigos empregadores.

\subsubsection{Imagem positiva da organização pública}

A maior parte dos entrevistados ressaltou o trabalho nas organizações pública como uma atividade relevante e valorizada, pois, por serem públicas, estariam contribuindo diretamente para o desenvolvimento do país:

O nome da empresa Y é muito forte, não é? É a maior empresa do Brasil, aí começa a cair a ficha. Não me preocupei muito com o salário, mas com o fato de estar trabalhando na empresa Y. (E8)

Além disso, havia o prestígio social de se trabalhar nessas organizações, o que reforça o argumento de Conway e Briner (2005) de que há influências externas à realidade vivida na organização que influenciam a opção por se trabalhar nela, como experiências anteriores e a opinião de pessoas de fora da empresa, como a de amigos e familiares.

Eu estava com a minha vida estável em Porto Alegre (...) Minha primeira reação foi ‘não 
vou', mas aí minha família começou a pressionar muito, e a partir daí que eu comecei a pesar os benefícios. (E4)

Uma outra questão relacionada à imagem da empresa que surgiu com frequência foi a expectativa de que a empresa em foco tivesse uma dinâmica análoga ao setor privado. Havia o interesse dos participantes em fazer parte de uma empresa que não fosse caracterizada como uma caricatura do serviço público improdutivo. Para explicar isso, os entrevistados falaram que essa organização deveria ter um "lado privado" (entrevistado 8):

(...) Outro fator que me atraiu foi que a empresa mais se assemelhava a um trabalho privado, porque eu também não queria ser um funcionário público daquele que fica na mesa o dia inteiro só esperando a hora de ir embora. (E2)

Eu também queria que fosse alguma coisa que eu me realizasse. Entrar pra uma prefeitura, por exemplo, pra ficar batendo carimbo, sei lá, não me atenderia. (E11)

Estas considerações dos entrevistados indicam que, além de boas condições de trabalho, associadas à remuneração e à estabilidade, esses indivíduos também buscam um senso de realização no trabalho, o que contraria, em certa medida, a visão estereotipada que caracteriza o funcionário público como um indivíduo acomodado, que busca, tão somente, condições de trabalho seguras e vantajosas.

\subsection{Ajuste inicial do contrato psicológico}

O ajuste inicial do contrato psicológico se inicia posteriormente à contratação. Nesse período, as expectativas dos trabalhadores são confrontadas com a realidade da rotina de trabalho e do ambiente da empresa pública, pois é nesse momento que o funcionário passa a conhecer melhor essas dinâmicas. $O$ entendimento desse ambiente é mediado por mensagens passadas pelos membros da organização por meio de pistas sociais e da socialização (ROUSSEAU, 1995). A partir dessas informações, o empregado começa a ter capacidade de desenvolver uma visão crítica sobre seu ambiente, tomando como base, inclusive, experiências de trabalho passadas. Esse exercício de comparação das experiências antigas com a atual esteve fortemente presente nos discursos dos entrevistados.

De acordo com Côrtes e Silva (2006), é na etapa inicial que são confirmadas (ou frustradas) as principais expectativas dos trabalhadores, por esse motivo trata-se de um momento chave no que se refere ao estabelecimento do contrato psicológico. Para apresentar os resultados obtidos, os relatos foram organizados em dois blocos: o primeiro reúne as expectativas iniciais que, segundo os entrevistados, foram confirmadas após o ingresso na organização, e o segundo, apresenta aspectos da organização e do trabalho que superaram as expectativas iniciais dos entrevistados. Cabe destacar que, apesar de Côrtes e Silva (2006) ressaltarem que nessa etapa de ajuste do contrato emergirem tanto pontos positivos quanto negativos, não houve, por parte dos entrevistados, menção a nenhuma frustração de expectativas.

\subsubsection{Expectativas iniciais confirmadas}

O momento do ajuste do contrato psicológico caracteriza-se pela incompletude dos termos entre as partes e pela noção ainda não totalmente desenvolvida do que esperar um do outro (CORTÊS e SILVA, 2006). Dessa forma, tanto empregador quanto empregado são levados a preencher os espaços em branco (ROUSSEAU, 1995). Além disso, de acordo com Lee et al. (2011), 
o cumprimento satisfatório do contrato terá reflexos no modo como os novos entrantes reagirão às condições de trabalho.

A respeito da jornada de trabalho, por exemplo, os funcionários se mostraram satisfeitos com o que vivenciaram nas empresas. Eles se declararam estar mais "donos do seu tempo" (entrevistada 1) depois de iniciarem seu novo contrato de trabalho:

Eu considero que eu tenho bastante responsabilidade, mas mesmo assim eu me sinto mais dona do meu tempo do que lá. Eu consigo me organizar, eu consigo organizar a minha agenda, eu consigo tirar férias sem peso na consciência. (E1)

O fato de assuntos relacionados à demissão e a reestruturações não fazerem parte das conversas entre os funcionários das empresas públicas também contribuiu para confirmar algumas expectativas iniciais relacionadas à estabilidade que o emprego ofereceria. $\mathrm{O}$ silêncio nas organizações públicas sobre esse assunto, portanto, teve o papel de importante pista social (CONWAY e BRINER, 2005) para alguns empregados, sinalizando que esta não era uma preocupação naquele contexto. Esta percepção foi corroborada pela ausência de exemplos de demissão nessas organizações, reforçando as expectativas de estabilidade desse grupo:

(...) Desde o início aquilo foi me dando uma motivação muito grande, estava feliz de trabalhar numa empresa em que eu poderia ficar o resto da vida trabalhando nela. (E1)

A terceira expectativa confirmada dizia respeito à remuneração atraente. O salário inicial das posições a serem ocupadas era de conhecimento dos entrevistados antes mesmo de sua entrada na empresa, o que garantiu que, em um primeiro momento, não houvesse surpresas quanto a essa questão. Todavia, para os empregados de todas as empresas, o conjunto de benefícios oferecidos foi uma surpresa positiva na composição da remuneração. Foram destacados itens como previdência privada, plano de saúde e auxílio educacional, aspectos que não estavam presentes nas expectativas iniciais, mas que, posteriormente, reforçaram a ideia de que a remuneração recebida era realmente atraente, passando a fazer parte dos termos que compunham o contrato psicológico dos novos funcionários públicos:

O salário melhorou depois que eu entrei. Eu só fui descobrir os benefícios quando estava na fila para entregar os documentos. Aí eu: 'caraca, tem isso, tem isso'. Não sabia nada. (E8)

A imagem positiva da instituiçãopública também foi confirmada pelos funcionários após o ingresso nas suas respectivas empresas. Alguns participantes destacaram que se sentem contribuindo para questões de âmbito nacional e que, por isso, entendem que suas atividades são valorizadas. Essa percepção a respeito do trabalho pode ser benéfica para a empresa, pois tanto a qualidade como a quantidade de trabalho estão ligadas à imagem da organização como um todo e não restritas às características imediatas do trabalho ou a incentivos monetários. Esse ponto está refletido nos relatos de alguns entrevistados que, mesmo afirmando entender que seu trabalho tem uma influência pequena na empresa como um todo, acreditam estar contribuindo para uma ação maior, para o objetivo final da organização:

Eu respeito demais a instituição, acho que ela tem um papel importante para o Brasil. Então eu quis fazer parte disso para fazer diferença para nossa economia. E eu me sinto produtivo, eu sinto que eu estou sendo uma gota no oceano, mas consigo fazer a minha parte. (E6) 
O prestígio que a empresa tem diante dos membros da sociedade que consequentemente se reflete no prestígio que se atribui àqueles que nela trabalham aparece no orgulho que os entrevistados sentem por fazerem parte dessas empresas:

Minha mãe lá no interior do Rio Grande do Sul, todo mundo sabe que eu trabalho na empresa Y. "Eu tenho uma filha que trabalha na empresa Y". É uma coisa. (E4)

A fala anterior se alinha com as considerações de Côrtes e Silva (2006), quando argumentam que a opinião da família tem um peso sobre a imagem da empresa e que essa imagem tem influência tanto no processo de decisão de ingresso quanto no ajuste inicial do contrato. Por fim, ao relatarem suas expectativas sobre o ritmo de trabalho nas empresas, definido, algumas vezes como "análogo ao do setor privado", os entrevistados mostraram-se positivamente surpreendidos. Esse aspecto é discutido no tópico seguinte.

\subsubsection{Expectativa superada: dinâmica de trabalho estimulante}

Os relatos dos entrevistados evidenciaram um aspecto que superou suas expectativas iniciais: a dinâmica estimulante de trabalho encontrada nas empresas. Nas entrevistas, os indivíduos sinalizaram que a escolha da empresa se deu pela expectativa de que a realidade de trabalho tivesse traços da dinâmica do setor privado, com características como dinamismo e competitividade e se diferenciassem de uma imagem caricatural de um funcionalismo público improdutivo. Segundo os entrevistados, essas expectativas não só foram confirmadas como superadas, pois estes relataram terem encontrado ambientes mais dinâmicos do que os anteriores:

É uma relação extremamente cordial, apesar de ser um ambiente também que é extremamente competitivo (...) É um ambiente em que você precisa estar sempre demonstrando resultado. (E5)

Além disso, alguns indivíduos afirmaram que a organização pública mostrava-se mais eficaz do que a privada, com rotinas de trabalho mais estruturadas e mais produtivas. Segundo os entrevistados, a cultura disseminada no setor privado da necessidade de horas extras torna as jornadas mais longas, porém menos produtivas, pois os funcionários tendem a diluir, durante o seu dia de trabalho, tarefas que poderiam ser feitas em menos tempo:

Eu acho que eu trabalho mais durante o tempo que eu passo aqui do que quando eu trabalhava lá, com certeza eu produzo mais (...) Eu acho que na auditoria tem essa cultura de você trabalhar muito, ficar até mais tarde, e as pessoas absorvem isso e acham natural, então elas produzem menos ao longo do dia. (E1)

O ritmo de absorção de novos conhecimentos também apareceu como uma característica vista de forma positiva no novo contexto de trabalho. Os entrevistados foram surpreendidos ao identificarem, nas organizações públicas, um ambiente em que essa demanda por aprendizado rápido existia, em alguns casos com intensidade até maior do que a encontrada nas empresas privadas. Essa dinâmica foi justificada pelos funcionários por diferentes razões, como a importância estratégica da organização ou pelo fato da empresa ter um grande leque de operações e, consequentemente, mais conhecimentos a serem absorvidos, conforme destacado abaixo:

O ritmo de absorção de novos conhecimentos aqui foi até maior do que na iniciativa privada, por alguma razão, não sei, talvez pelo tamanho da empresa, talvez tivesse mais coisas para aprender aqui do que eu tinha para aprender lá. (E1) 
Cabe destacar, nesse tópico, um fato incomum no processo de ajuste inicial do contrato psicológico: os indivíduos serem surpreendidos, positivamente, por aspectos encontrados na organização que não haviam sido vislumbrados antes do ingresso. Conforme ressaltam Morrison e Robinson (1997), violações de contrato tendem a ser corriqueiras na relação estabelecida entre empregado e empregador, pois os indivíduos costumam superestimar as promessas e ofertas das organizações.

\subsection{Reavaliação do contrato psicológico}

No momento das entrevistas, todos os sujeitos encontravam-se na fase de reavaliação do contrato, isto é, em uma fase posterior ao ajuste inicial, na qual o contrato psicológico já havia amadurecido, e o fator continuidade contribuiu para reforçar a relação de troca entre empregador e empregado. Dois questionamentos na entrevista tiveram o objetivo de provocar a reflexão dos entrevistados sobre como estaria a relação deles com a organização atualmente: perguntou-se aos participantes o que os fazia permanecer na empresa em que trabalhavam, bem como o que os motivaria a sair dela. A partir daí, os indivíduos expuseram os pontos mais importantes no que diz respeito à reavaliação do contrato psicológico.

\subsubsection{Termos do contrato reavaliados}

De acordo com Rousseau (1995), os conceitos que formam os contratos, bem como os fatores que os influenciam, vão se consolidando ao longo do tempo e formando, assim, modelos mentais de atuação. Este fato é ratificado no discurso dos entrevistados ao se verificar que há expectativas que foram formadas antes mesmo desses indivíduos entrarem na organização e que reaparecem quando se questiona aos entrevistados sobre cada uma das etapas do contrato psicológico. Essas expectativas iniciais - a estabilidade no emprego, a remuneração atrativa, a jornada de trabalho moderada e a imagem positiva da empresa - foram confirmadas pelos indivíduos e contribuíram para consolidar a relação com a empresa.

Ainda segundo Rousseau (1995), a consolidação dos termos do contrato e a formação de modelos mentais de atuação levam à automaticidade, que seria um modelo de pensamento em que esses termos estão presentes de maneira tão arraigada que não se consegue pensar sem eles e nem mais se percebe que eles estão presentes na estrutura dos pensamentos e decisões. Quando é mencionada a estabilidade, por exemplo, esse fato aparece. Alguns entrevistados tiveram dificuldade em visualizar a possibilidade de saída da empresa quando questionados sobre os fatores que os levariam a sair. A estabilidade é, portanto, um aspecto crucial no contrato psicológico estabelecido:

Nossa! Eu acho que a única coisa que eu consigo vislumbrar é se a minha empresa começar a ter um papel reduzido no cenário nacional e fizer demissões. Aí, isso vai gerar uma insegurança grande. (E1)

Eu não visualizo nenhum fator que me levaria a deixar a empresa (...) Logicamente, se acontecer uma proposta irrecusável, mas eu não visualizo essa possibilidade. (E3) Olha, deixar a minha empresa hoje... Só se acontecer uma hecatombe nuclear. (E6)

A jornada de trabalho contratual, em que há pouca frequência de horas extras, também foi considerada como um ponto importante na reavaliação do contrato. A esse aspecto também 
está associada à questão da qualidade de vida proporcionada pelo cumprimento da jornada. Ao abordarem essa questão, os entrevistados fizeram comparações com suas experiências nas empresas privadas e argumentaram sobre a possibilidade de se dedicarem mais a atividades pessoais proporcionada pelo fato de trabalharem "apenas" oito horas diárias. A ideia da reciprocidade que deve existir na relação entre empregador e empregado também foi abordada por um dos entrevistados, conforme relato a seguir:

Eu consigo sair no horário pra fazer meu curso de inglês, coisa que eu não conseguia fazer antes. Às vezes a empresa te cobra, mas ela não te dá o subsídio pra isso e, às vezes, o insumo básico pra isso é simplesmente a disponibilidade. (E5)

A análise dos relatos obtidos mostrou que existem expectativas que apareceram no momento anterior à entrada dos funcionários na empresa e que foram consideradas atendidas, inclusive na fase de reavaliação do contrato, o que pode ser entendido como cumprimento do contrato psicológico. Lee et al. (2011) argumentam que a percepção de contrato cumprido pelo empregado pode funcionar como uma forma de controle cognitivo por parte da organização, reforçando os laços entre o trabalhador e a empresa. Os autores destacam essa questão ao tratar da importância em se cumprir aquilo que é prometido.

\subsubsection{Novos motivos para a permanência na organização}

Ainda sob a influência das perguntas que questionavam o porquê da opção dos entrevistados por permanecerem em suas empresas e quais seriam as variáveis que os levariam a sair, novos elementos foram considerados importantes pelos entrevistados. Conforme destaca Rousseau (1995), o contrato psicológico se modifica com o tempo, já que o processo de reunir informações sobre a empresa muda bastante do primeiro para o terceiro ano na organização. Dessa forma, dois novos aspectos surgiram nas falas dos entrevistados como influenciadores na decisão de permanecer na organização e, portanto, como itens acrescidos ao contrato psicológico estabelecido. Estes são o incentivo à educação que as organizações oferecem aos funcionários e a possibilidade de crescimento profissional.

A questão do incentivo à educação surge, pela primeira vez, no momento de reavaliação do contrato. Esse aspecto não havia aparecido como uma expectativa ou um motivador para se trabalhar nas empresas. Somente após uma socialização maior na empresa é que esses indivíduos identificaram o incentivo educacional como um fator importante que justifica sua permanência na organização escolhida. O surgimento de novos elementos ocorre porque, uma vez no emprego, as experiências de socialização consolidam um contrato mais completo (LEE et al., 2011). Os relatos seguintes ilustram esse novo ponto acrescentado aos contratos:

Um ponto interessante foi o programa de incentivo à pós-graduação (...) Você pode ficar um tempo fora estudando, se dedicando, existe a possibilidade de ir para o exterior, então pra mim é uma coisa muito importante. (E3)

O meu mestrado é todo bancado pela empresa Y, se não fosse a empresa Y eu não estaria fazendo mestrado hoje. (E4)

Eu acho a questão do treinamento muito boa... Eles oferecerem para o funcionário essa possibilidade de você estar sempre se atualizando, sempre buscando se manter atualizado, informado, e investir nisso é importante. Porque geralmente querem que você se atualize, mas por conta própria. (E13)

Conforme mencionado, os participantes destacaram também a possibilidade de cresci- 
mento profissional dentro das organizações como um dos motivos de permanência nas mesmas. A obtenção de cargos comissionados, um dos exemplos de crescimento, é indicada como uma questão motivadora, tanto pelos fatores ligados à obtenção de poder em uma nova posição hierárquica como pelos ganhos financeiros que estão ligados a esse processo. De acordo com Robinson, Kraatz e Rousseau (1994), as trocas entre as partes mudam juntamente com os fatores ambientais, e a percepção do empregado se modifica juntamente com isso. Essa afirmativa se alinha com o surgimento desse novo ponto que é agregado com a maturidade dessa relação.

Então assim, e eu gosto da forma como é levado, porque assim, apesar de ser uma iniciativa pública se parece muito com a iniciativa privada nessa questão da promoção... Você tem uma carreira, você tem como subir, sabe? Eu gosto bastante disso. (E13)

Os autores também afirmam que os funcionários não avaliam apenas o comportamento do empregador, mas também o seu próprio, modificando suas posturas em coerência com a nova realidade ambiental. Essa afirmativa é exemplificada nas falas dos entrevistados sobre crescimento profissional, em que eles mostram não apenas haver uma expectativa de cumprimento da promessa por parte da empresa, mas que mudaram algumas de suas ações para também garantir que essas promessas sejam cumpridas:

Hoje estou num grupo de potenciais gerentes (...) A empresa está me dando insumos (...) Eu estou pegando também mais responsabilidades, a empresa está me dando retorno, então eu estou vendo que a minha carreira está progredindo. (E8)

Esse indivíduo mostra, de forma clara, essa relação de troca e explicita que compreende que a organização está lhe "dando insumos" e, em contrapartida, oferece mais dedicação ao assumir mais responsabilidades. A possibilidade de crescimento profissional surge como uma nova demanda da relação amadurecida entre empresa e empregado que, se não atendida, pode gerar a insatisfação e uma possível saída do funcionário da organização.

A análise desta última etapa do processo de estabelecimento do contrato psicológico confirmou o exposto no modelo de Côrtes e Silva (2005): é nesta fase que o contrato, que se inicia antes mesmo do ingresso na empresa, se consolida ou se rompe. No caso em estudo, a julgar pelas respostas dos entrevistados, a consolidação foi a regra, não havendo entre os entrevistados um único indivíduo que apontasse violações deste contrato.

\subsection{O contrato psicológico como um processo}

Entendido como um processo, o contrato psicológico vai se consolidando no decorrer da relação que o trabalhador estabelece com a organização na qual está inserido, relação esta que é iniciada antes mesmo deste ingressar na organização. A natureza processual deste contrato revela sua dinâmica e complexidade, indicando o quão desafiador é, para as organizações, gerenciarem a ligação subjetiva da sua força de trabalho. A análise dos relatos dos entrevistados acerca do estabelecimento dessa relação com suas respectivas empresas revelou aspectos importantes, que são sintetizados nesta sessão.

Conforme foi discutido, o que inicialmente atraiu os entrevistados para o trabalho na PETROBRÁS, no Banco Central e no BNDES foi a perspectiva de trabalhar "apenas" quarenta horas contratuais ou até menos, como no caso do BNDES que pratica jornada de trabalho de sete horas diárias. Para os entrevistados, essa questão era particularmente importante por possibilitar-lhes 
organizar e desfrutar melhor a vida fora do trabalho, fato apontado como de difícil conciliação quando da atuação na iniciativa privada. A estabilidade no emprego e a remuneração atraente, atualmente oferecidas nessas e em outras organizações públicas de "elite", também tiveram papel importante no estabelecimento do contrato psicológico inicial entre os entrevistados e suas respectivas empresas. A esses aspectos somou-se, ainda, a visibilidade e a imagem positiva das organizações em questão, evidenciando que o senso de pertencimento a um coletivo valorizado e a ideia de realizar um trabalho relevante para a sociedade são aspectos importantes para os profissionais entrevistados.

Ao buscar entender os fatores que constituem o contrato psicológico dos entrevistados, a análise não se limitou a conhecer apenas os motivos iniciais dessa escolha: a opção por olhar o contrato em sua perspectiva processual, como proposta por Côrtes e Silva (2006), permitiu identificar os elementos que atraíram os profissionais às organizações, bem como os motivos que os mantêm nas mesmas, reforçando o contrato firmado entre as partes. Ao serem indagados acerca da confirmação de suas expectativas iniciais sobre a empresa, os entrevistados relataram que, além de terem essas expectativas atendidas, foram surpreendidos por uma dinâmica de trabalho estimulante, semelhante à vivenciada na iniciativa privada, segundo alguns. Essa questão parece ser particularmente valiosa para alguns entrevistados, que temiam encontrar nessas empresas um ritmo de trabalho desestimulante.

Finalmente, ao explicarem o que os mantêm nas empresas - fase identificada por Côrtes e Silva (2006) como crítica por pressupor uma reavaliação do contrato psicológico estabelecido - os entrevistados não só ratificaram terem tido suas expectativas iniciais atendidas, como acrescentaram o incentivo à educação e a possibilidade de crescimento profissional como aspectos valiosos para sua permanência na empresa. Pode-se dizer, com base nos relatos obtidos, que os entrevistados além de terem suas expectativas iniciais confirmadas, ao se integrarem às empresas nas quais atuam, ainda foram surpreendidos por aspectos positivos que desconheciam e que contribuíram para a consolidação do contrato psicológico estabelecido com as empresas, reforçando seus laços com estas organizações.

\section{CONSIDERAÇÕES FINAIS}

O objetivo inicial deste trabalho foi entender o que motiva profissionais qualificados a trabalhar em grandes organizações públicas, com ênfase nos elementos que compõem o contrato psicológico estabelecido entre estes e as organizações. A análise dos relatos obtidos, primeiramente, trouxe à tona questões relevantes para o entendimento do que atraiu os trabalhadores para as organizações do primeiro setor pesquisadas, identificando os fatores formadores das bases desses contratos psicológicos, o que possibilita, a essas organizações, compreenderem os principais pontos de atenção na relação com seus funcionários.

De forma conclusiva, cabe ressaltar que a análise do processo de estabelecimento do contrato psicológico empreendida neste trabalho trouxe duas contribuições relevantes para o debate acerca desta temática. A primeira diz respeito à constatação do destaque dado pelos entrevistados aos aspectos positivos encontrados nas organizações em que atuam, a exemplo da possibilidade de crescimento profissional, aspecto este inesperado - e muito bem recebido pelos entrevistados - o que contribuiu para reforçar os laços estabelecidos com as organizações em foco e, portanto, consolidar o contrato psicológico. Nesse sentido, os achados da pesquisa indicam que a evolução do processo de estabelecimento do contrato psicológico pode ser tanto pautada por perdas identificadas pelos funcionários, que delineiam as denominadas violações 
do contrato, como por ganhos, expressos na forma de recompensas ou outros aspectos positivos que não eram vislumbrados pelos trabalhadores, antes do ingresso nas organizações. Estes ganhos, todavia, tendem a ser pouco explorados na literatura que discute o contrato psicológico, mais pródiga em entender o que gera a violação do que o fortalecimento do contrato (MENEGON e CASADO, 2012).

Nesse sentido, a análise empreendida, ao revelar que os entrevistados, além de não acusarem qualquer violação do contrato, terem se mostrado positivamente surpreendidos com contornos do trabalho que não imaginavam encontrar nas organizações em foco, como a dinâmica de trabalho estimulante, as rotinas de trabalho estruturadas e o ritmo de absorção de novos conhecimentos intenso, chamou atenção para um aspecto que merece mais estudos: entender as condições que propiciam o fortalecimento do contrato psicológico. Destaca-se, assim, a principal implicação acadêmica deste estudo: revelar aspectos subjacentes ao fortalecimento do contrato psicológico estabelecido entre trabalhadores e empresas.

Um segundo aspecto a ser destacado diz respeito ao fato de que a análise dos fatores que delinearam o contrato psicológico de funcionários de organizações públicas, egressos do setor privado, revelou não só o que esses indivíduos valorizam em seus empregos atuais, mas também o que os deixava insatisfeitos nos empregos anteriores. Aspectos como a jornada de trabalho reduzida e a estabilidade foram os principais pontos valorizados nas novas empresas, por seu contraste com as situações anteriormente vividas pelos entrevistados.

A constatação da rejeição dos profissionais entrevistados a condições de trabalho que vêm se tornando comuns, em boa parte das empresas privadas brasileiras, na última década, pode ser particularmente importante, em um momento em que se alardeia um "apagão de talentos" no Brasil. Por este motivo, entender o que trabalhadores qualificados como os entrevistados valorizam pode ser de extrema valia, não só para o setor público, mas para todas as organizações que precisam atrair e reter em seus quadros profissionais qualificados e motivados. Em outros termos, postula-se que a atratividade que o setor público vem exercendo sobre uma parcela importante da força de trabalho brasileira revela aspirações relativas a condições de trabalho que talvez não sejam exclusivas dessa parcela de profissionais, mas comum a boa parte da força de trabalho, atuante ou não em organizações públicas. Não é exagero especular que bons salários, estabilidade no emprego e jornadas de trabalho não abusivas sejam aspirações da maior parte dos trabalhadores e que, a julgar pelos relatos dos entrevistados essas condições não vêm sendo oferecidas no setor privado. Nesse sentido, no que tange a suas implicações gerenciais, o presente estudo aponta às organizações públicas ou privadas possíveis caminhos para o fortalecimento dos contratos psicológicos estabelecidos com os trabalhadores.

Os achados da presente pesquisa permitem sugerir, como desdobramentos de estudos futuros, a ampliação da base de pesquisa, incluindo funcionários de organizações públicas que possuem realidades de trabalho menos favoráveis do que aqueles que atuam no Banco Central, BNDES e PETROBRÁS, com vistas a analisar em que medida o cenário positivo retratado pelos entrevistados deste estudo são específicos destas instituições. Também seria interessante fazer um estudo longitudinal, acompanhando um mesmo grupo de indivíduos em sua trajetória de inserção na empresa estudada, com vistas a acompanhar o processo de estabelecimento do contrato psicológico, pois, no presente estudo, os entrevistados falaram do processo de estabelecimento do contrato psicológico, a partir do ponto de vista de sua situação atual, na qual o contrato já estava consolidado. Finalmente, realizar pesquisa análoga à presente, porém com indivíduos que trabalham em empresas privadas, ofereceria um excelente contraponto aos resultados encontrados nesta pesquisa. 


\section{REFERÊNCIAS}

AMORIM, M. Tensão e Silêncio. Jornal O Globo. Rio de Janeiro, ano LXXXVIII, n. 2970, p. 1-3, 10 de março de 2013. Caderno Boa Chance.

ARGYRIS, C. Understanding Organizational Behavior. Homewood, Illinois: The Dossey Press, Inc., 1960.

BARDIN, L. Análise de conteúdo (L. de A. Rego \& A. Pinheiro, Trads.). Lisboa: Edições 70, 2006.

CONWAY, N.; BRINER, R. Understanding psychological contracts at work: A critical evaluation of theory and research. Oxford: Oxford University Press, 2005.

CONWAY, N.; BRINER, R. B. Understanding Psychological Contracts at Work: A Critical Evaluation of Theory and Research. New York: Oxford, 2006.

CÔRTES, L. L.; SILVA, J. R. G. Construção do contrato psicológico de indivíduos que ingressam em organizações do setor público no atual contexto brasileiro: estudo de caso em uma empresa estatal. In: XXX ENCONTRO ANUAL DA ASSOCIAÇÃO NACIONAL DE PÓS-GRADUAÇÃO E PESQUISA EM ADMINISTRAÇÃO - ENANPAD. Anais... Salvador, 2006. p.1-16.

DABOS, G.; ROUSSEAU, D. M. Mutuality and reciprocity in the psychological contracts of employee and employer. Journal of Applied Psychology, v. 89, p. 52-72, 2004.

GODOY, A.S. Introdução à pesquisa qualitativa e suas possibilidades. Revista de Administração de Empresas, São Paulo, 35 (2), p.57-63, 1995.

GUEST, D. The psychology of the employment relationship: an analysis based on the psychological contract. Applied Psychology: an International Review, v. 53(4): p. 541-555, 2004.

GUEST, D.; CONWAY, N. Communicating the psychological contract: an employer Perspective. Human Resource Management Journal, v. 12(2), p. 22-38, 2002.

LEE, C.; et al. Inducements, contributions, and fulfillment in new employee psychological contracts. Human Resource Management, v. 50, n.2, p. 201-226, 2011.

LEE, C.; LIU, J.; ROUSSEAU, D. M.; HUI, C.; ZHEN, X. C. Inducements, contributions, and fulfillment in new employee psychological contracts. Human Resource Management, v. 50, n.2, p. 201-226, 2011.

LEVINSON, H. et al. Men, Management, and Mental Health. Cambridge, MA: Harvard University Press. 1962.

MCFARLANE, S. L.; TETRICK, L. E. The Psychological Contract as an Explanatory Framework in the Employment Relationship, In: Cooper, C. L. and Rousseau, D. M., Trends in Organizational Behavior, Vol. 1, pp. 91-109, John Wiley e Sons, Londres. 1994.

MENEGON, L. CASADO, T. Contratos psicológicos: uma revisão da literatura. R. Adm. São Paulo, v.47, n.4, p. 571-580, 2012.

MOLON F. S.; MELLO, S.P.T.; TORRES, I.A.C. O que se discute sobre gestão por competências no setor público: um estudo preliminar das construções. Rev. Adm. UFSM, Santa Maria, v. 6, número 
4, p. 685-693, dez. 2013.

MORRISON, E. W.; ROBINSON, S. L. When employees feel betrayed: A model of how psychological contract violation develops. Academy of Management Review, v. 22, p. 226-256, 1997.

ROBINSON, S. L.; KRAATZ, M. S.; ROUSSEAU, D. M. Changing obligations and the psychological contract: a longitudinal study. Academy of Management Journal, v. 37, p. 137-152, 1994.

ROBINSON, S. L.; MORRISON, E. W. Psychological Contracts and OCB: The Effect of Unfulfilled Obligations on Civic Virtue Behavior. Journal of Organizational Behavior, v. 16, p. 289-298. 1995.

RORATO, R.; DIAS, E.D. Cultura Organizacional no Setor Público: um Estudo Junto a um Departamento Administrativo de uma Universidade Federal Brasileira. Rev. Adm. UFSM, Santa Maria, v. 4, n. 3, p. 341-351 set./dez. 2011.

ROUSSEAU, D.M. Psychological and Implied contracts in organizations. Employee Responsibilities and Rights Journal, vol. 2, p. 121-139, 1989.

ROUSSEAU, D.M. Developing psychological contract theory. In: SMITH, K.G.; HITT, M.A. Great Minds in Management: The Process of Theory Development (p. 190-214). Oxford, UK: Oxford University Press, 2005.

ROUSSEAU, D. M. Psychological contracts in organizations: understanding Written and unwritten agreements. California: Sage Publications, 1995.

ROUSSEAU, D. M. Changing the deal while keeping the people. Academy of Management Executive, v. 1, n.10, p. 50-58, 1996.

SCHEIN, E. H. Organizational Psychology. Prentice-Hall, Englewood Cliffs, NJ. 1965.

SILVA, F.A.; GONÇALVES, C.A. O Processo de Formulação e Implementação de Planejamento Estratégico em Instituições do Setor Público. Rev. Adm. UFSM, Santa Maria, v. 4, n. 3, p. 458-476 set./dez. 2011.

WETZEL, U. Transformação do Contrato Psicológico no Contexto da Privatização: Estudo de Casos. Revista de Administra 